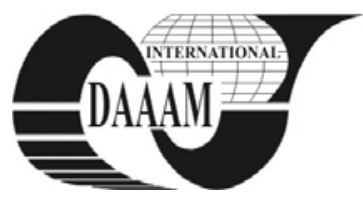

Annals of DAAAM for 2011 \& Proceedings of the 22nd International DAAAM Symposium, Volume 22, No. 1, ISSN $1726-9679$ ISBN 978-3-901509-83-4, Editor B. Katalinic, Published by DAAAM International, Vienna, Austria, EU, 2011 Make Harmony between Technology and Nature, and Your Mind will Fly Free as a Bird Annals \& Proceedings of DAAAM International 2011

\title{
ACCELERATED CARBIDE SPHEROIDISATION IN 100CR6 STEEL
}

\author{
HAUSEROVA, D[aniela]; DLOUHY, J[aromir]; NOVY, Z[bysek] \& ZRNIK, J[ozef]
}

\begin{abstract}
The importance of bearing steels in industrial production is continuously increasing. These steels are not fit for working unless soft-annealed. The purpose of this annealing process is to obtain globular carbides which will be uniformly distributed in the matrix. Conventional methods of annealing steel stock to obtain globular pearlite require long soaking times: up to several tens of hours, which is due to the diffusional nature of the process. The research into rapid carbide spheroidisation aims to significantly shorten selected heat treatment processes. The present paper presents investigation of rapid carbide spheroidisation and a decrease in hardness in 100Cr6 bearing steel. The newly designed schedules are several times shorter than conventional heat treating procedures. This brings a vast potential in this area Key words: accelerated spheroidisation, pearlite, globular carbide, 100Cr6 bearing steel, soft annealing
\end{abstract}

\section{INTRODUCTION}

Carbide spheroidisation is a significant metallurgical process which contributes to general changes in microstructure during annealing processes (Nam \& Bae, 1999). Current processes leading to carbide spheroidisation rely on diffusion of carbon in steel heated to a temperature close to or slightly below $A_{c 1}$ (Ghosh, 2010). Diffusion-based processes of this type are time-consuming. The holding times of up to tens of hours (Ata \& Meisam, 2010) make soft annealing one of the most expensive heat treatment processes. During annealing, softening and, in some cases, recrystallization processes take place (Jech, 1983). The process which was newly designed by the company COMTES FHT reduces the processing time for carbide spheroidisation several times and therefore yields considerable cost savings. The present paper explores the effect of the newly-designed thermal schedules on the carbide spheroidisation behaviour and on decrease in hardness in bearing steel grade 100Cr6.

\section{EXPERIMENTAL}

The experimental material was a bearing steel grade 100Cr6 with a chemical composition given in Table 1. The initial microstructure consisted of pearlite with a small amount of cementite precipitated along prior austenite boundaries (Fig. $1)$. The initial material was hot forged. Its hardness was 351 HV10.

\subsection{Heat Treatment}

The heat treatment process was designed to promote accelerated carbide spheroidisation leading to reduced hardness of the material.

\begin{tabular}{|c|c|c|c|c|c|c|c|}
\hline & $\mathrm{C}$ & $\mathrm{Si}$ & $\mathrm{Mn}$ & $\mathrm{P}$ & $\mathrm{S}$ & $\mathrm{Cr}$ & $\mathrm{Mo}$ \\
\hline From & 0.93 & 0.15 & 0.25 & - & - & 1.35 & - \\
\hline To & 1.05 & 0.35 & 0.45 & 0.025 & 0.015 & 1.60 & 0.10 \\
\hline
\end{tabular}

Tab. 1. Chemical composition of the 100Cr6 steel according to ISO 683-17 [weight\%]

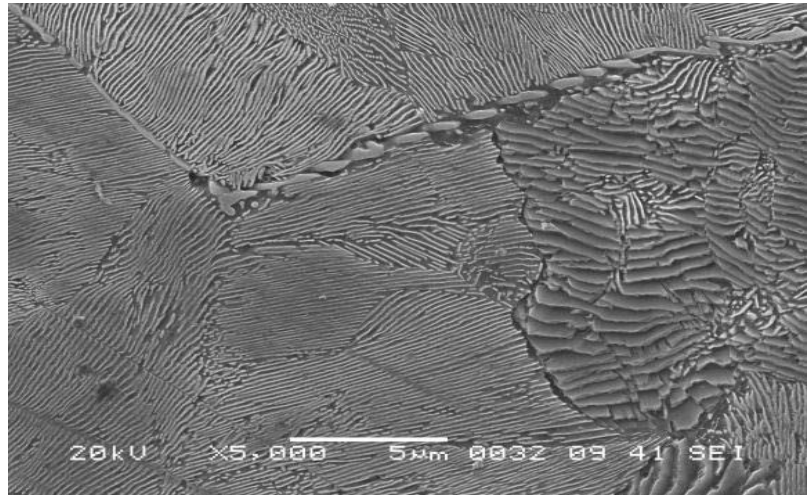

Fig. 1. Initial microstructure of $100 \mathrm{Cr} 6$ with hardness of 351 HV10

This heat treatment experiment was conducted in the quenching dilatometer Linseis L78 RITA (Rapid Induction Thermal Analysis), in which the specimens were heated by electrical induction and cooled by flowing gas. The dilatometer allows the specimen temperature to be controlled precisely and with a very short response time during heating and cooling at a rate up to $200^{\circ} \mathrm{C} / \mathrm{s}$. Furthermore, it records the changes in length, time and temperature of phase transformations. The heat treate specimens were $3 \mathrm{~mm}$ in diameter and $10 \mathrm{~mm}$ in length.

The first schedule to be carried out involved partial austenitization and subsequent transformation to pearlite upon cooling (schedule code H30 - Fig. 2) (Howell, 1998). It comprised heating to the temperature of partial austenitization at the rate of $50^{\circ} \mathrm{C} / \mathrm{s}$, and 30 -second hold above $\mathrm{A}_{\mathrm{c} 1}$. The precise temperature was set at $775^{\circ} \mathrm{C}$. After analysing the results, a schedule with reduced austenitizing time of 15 seconds was designed (H15-1). The following schedules included repeated cycles of austenitizing and subsequent austenite decomposition. The maximum temperature in these cycles was $775^{\circ} \mathrm{C}$ and the minimum one was $650^{\circ} \mathrm{C}$. These temperature cycles were repeated twice and three times (schedules H15-2, H15-3). The longest schedule took 250 seconds.

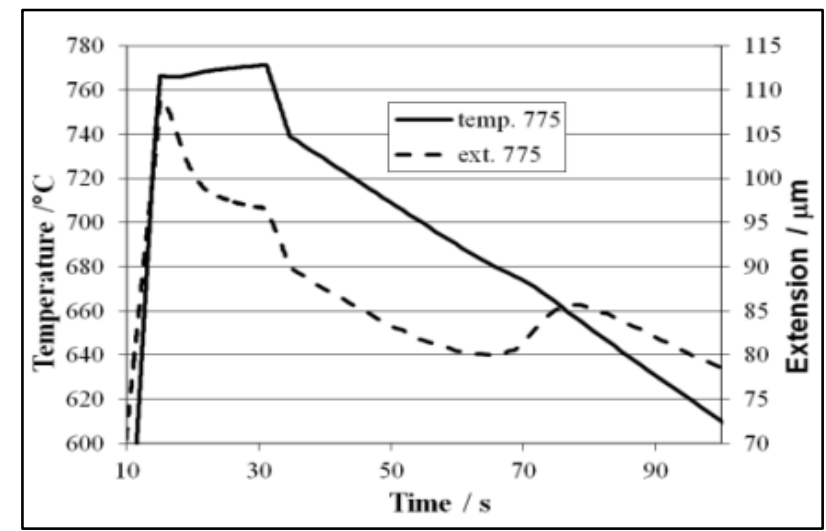

Fig. 2. Diagram of H30 schedule 


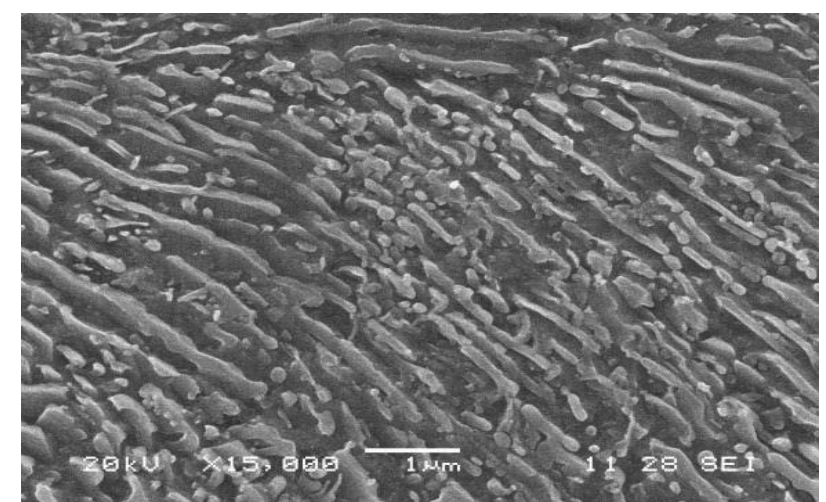

Fig. 3. Microstructure of schedule H30 - hardness 288 HV10

\section{RESULTS AND DISCUSSION}

The dilatometer curve for the H30 schedule (Fig. 2) shows austenitization taking place in the material over the course of the thirty-second hold above $A_{c 1}$. Metallographic observation of the microstructure revealed that this schedule did not lead to complete conversion of original cementite lamellae. Original cementite lamellae were discernible, disintegrating into globular or bar-like fragments. Among them, there were scarce fine lamellae of new cementite formed during austenite decomposition (Fig. 3). The hardness of this sample was 288 HV10.

In order to prevent formation of fine new cementite lamellae, the austenitizing time was reduced to 15 seconds (H15-1). Metallographic observation revealed that in this case fine new cementite lamellae did not form. Disintegration of initial cementite lamellae was not as extensive as in the previous schedule which comprised a 30-second hold (H30). The shorter hold led to a slight increase in hardness of the specimen treated with the H15-1 schedule: 305 HV10.

For the carbide spheroidisation to be as complete as possible, the following schedules included austenitizing and subsequent austenite decomposition cycles which were repeated two and three times (H15-2, H15-3). The trends in microstructure evolution were apparent in metallographic analysis. The disintegration of cementite lamellae became more pronounced with increasing number of cycles (Fig. 4). With 3 cycles, the spheroidisation of cementite is almost complete. Hardness of the specimen H15-2 was 289 HV10. Hardness of specimen H15-3 was 277 HV10.

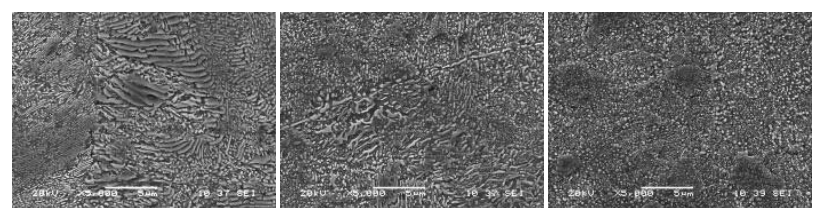

Fig. 4. Microstructures upon schedules H15-1, H15-2, H15-3

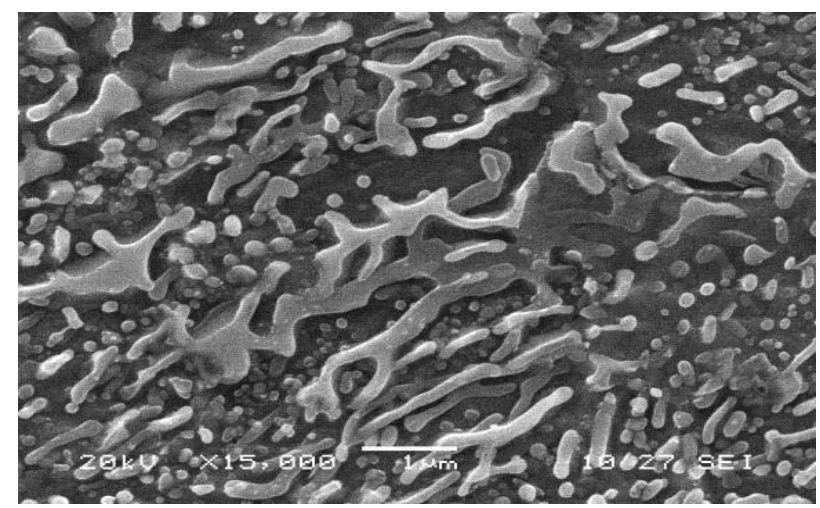

Fig. 5. Microstructure upon schedule H15-2: hardness 289 HV10

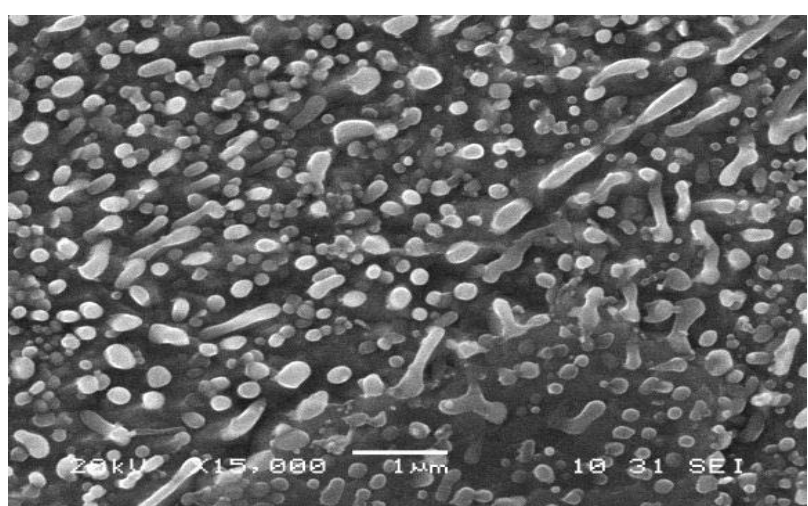

Fig. 6. Microstructure of schedule H15-3 - hardness 277 HV10

\section{CONCLUSION}

Heat treatment of $100 \mathrm{Cr} 6$ bearing steel in the quenching dilatometer produced a microstructure with spheroidised carbides and reduced hardness. The initial hardness of 351 HV10 decreased to the final value of 277 HV10.

Microstructure of the sample which underwent one 30 seconds hold is composed of the mixture of both original and new cementite lamellae. Original lamellae are partialy fragmented. The 30 -second hold above $A_{c 1}$ was too short to allow full dissolution of original cementite particles. However, it led to formation of fine new cementite particles in the course of austenite decomposition.

Schedules comprising repeated cycles of austenitizing and subsequent austenite decomposition produced a microstructure with almost fully spheroidised carbides. The fraction of spheroidised carbides increased and hardness decreased with the growing number of thermal cycles.

The basis of accelerated carbide spheroidisation is shortrange diffusion of carbon. These heat treatment schedules significantly reduced the time required for carbide spheroidisation from several hours to minutes.

Next research will be focused on further hardness decrease and carbide morphology optimization and quantitative analyses of ratio of spheroidised carbides and nonspheroidised carbides.

\section{ACKNOWLEDGEMENTS}

This paper includes results achieved under the project GACR P107/10/2272: Accelerated Carbide Spheroidization and Grain Refinement in Steels.

\section{REFERENCES}

Ata K. G. \& Meisam S. A. (2010). Spheroidising Kinetics and Optimization of Heat Treatment Parameters in CK60Steel Using Taguchi Robust Design. Journal of Iron and Steel Reasearch, Vol. 17, No. 4, 45-52, ISSN 1006-706X

Ghosh S. (2010). Rate-controlling parameters in the coarsening kinetics of cementite in $\mathrm{Fe}-0.6 \mathrm{C}$ steels during tempering. Scripta Materialia, Vol. 63, No. 3, 273-276, ISSN 13596462

Howel P. R. (1998). The Pearlite Reaction in Steels: Mechanisms and Crystallography. Elsevier Science Inc., Vol. 227-260. ISSN 1044-5803

Jech J. (1983). Tepelné zpracování oceli. SNTL Nakladatelství technické literatury

Nam W. J. \& Bae C. M. (1999). Coarsening Behavior of Cementite Particles at a Subcritical temperature in a medium Carbon Steel. Scripta Materialia, Vol. 41, No. 3, 313-318, ISSN 1359-6462 